\title{
Introduction and acceptance of novel endophyte tall fescue in the USA
}

\author{
D.M. BALL ${ }^{1}$, G.D. LACEFIELD ${ }^{2}$, C.S. AGEE ${ }^{3}$ and C.S. HOVELAND ${ }^{4}$ \\ ${ }^{1}$ Auburn University, 120 Extension Hall, Auburn University, AL 36849 \\ ${ }^{2}$ University of Kentucky, P.O. Box 469, Princeton, KY 42445 \\ ${ }^{3}$ Pennington Seed, Inc., P.O. Box 290, Madison, GA 30650 \\ ${ }^{4}$ University of Georgia (ret.). Dept. of Crop and Soil Sciences, Athens, GA 30602-7272
}

balldon@auburn.edu

\begin{abstract}
Release of the cultivar 'Kentucky 31' in 1943 led to widespread planting of tall fescue in the USA. An endophytic fungus (Neotyphodium coenophialum) usually present in this grass produces compounds that enhance competitiveness and survival of tall fescue in many environments, but it also produces ergot alkaloids implicated in the cause of animal disorders. Screening of hundreds of fungus strains identified some that do not produce high levels of ergot alkaloids. A "novel" endophyte strain was inserted into University of Georgia-developed cultivars 'Georgia 5 ' and 'Jesup' and became commercially available under the name $\mathrm{MaxQ}^{\mathrm{TM}}$ in 1999. It is estimated that at present there are some 121,000 hectares of novel endophyte tall fescue in at least 35 USA states. Persistence has been good and animal performance has been excellent. It is expected that novel endophyte tall fescue area will continue to increase in the USA in the future.
\end{abstract}

Keywords: novel endophyte, tall fescue, Neotyphodium, $\mathrm{MaxQ}^{\mathrm{TM}}$

\section{Introduction}

Tall fescue (Festuca arundinacea Schreb.) is native to Europe, but was planted and evaluated at several locations in the USA as early as the latter part of the nineteenth century (Buckner et al. 1979). It was only given serious consideration as a forage crop as a result of a chance observation in 1931 of a volunteer stand on a farm in eastern Kentucky by Dr. E.N. Fergus, a Professor of Agronomy at the University of Kentucky. He collected seed for further testing, resulting in release of the variety 'Kentucky 31' in 1943 (Fergus \& Buckner 1972). This new cultivar was widely planted during the 1940s and 1950s, and in 1973 was estimated to occupy 12 to 14 million ha (Buckner et al. 1979), mostly in the eastern USA.

Unfortunately, several livestock disorders have long been associated with the grass. In the late 1970s fescue toxicity, the most economically important of these disorders, was linked with the presence of the fungal endophyte Neotyphodium coenophialum (Bacon et al. 1977; Hoveland et al. 1983). This endophyte, originally identified as Epichloe typhina and later as Acremonium coenophialum, is exclusively seed transmitted (Bacon \& Siegel 1988). Most tall fescue fields in the USA are highly infected with this fungus (Shelby \& Dalrymple 1987) indicating the endophyte must have been distributed in seed of the variety Kentucky 31. Subsequently, ergot alkaloids, long known to cause toxicities (Bacon et al. 1986) produced by the fungus were implicated as the cause of the disorders of animals grazing "toxic endophyte" tall fescue.

Many experiments comparing tall fescue having low and high levels of endophyte infection were soon conducted. A summary of experiments (Schmidt \& Osborne 1993) included a report of tests conducted in 10 states in which daily gains of beef steers averaged $0.28 \mathrm{~kg}$ lower when animals consumed high-endophyte tall fescue pasture. In two other tests with steers in Alabama, in one of which animals were fed hay and in the other seed, animal daily gain was $0.28 \mathrm{~kg}$ and $0.50 \mathrm{~kg}$ lower, respectively, with high-endophyte tall fescue. Performance of cows and calves in five grazing experiments in different states showed daily gain of cows, and daily gain of calves averaged $0.23 \mathrm{~kg}$ and $0.19 \mathrm{~kg}$ lower, respectively, on high-endophyte tall fescue. Data reported from four of these tests showed cow pregnancy rates averaged $87 \%$ on endophyte-free and $47 \%$ on endophyte-infected tall fescue, respectively.

Endophyte-free fescue became commercially available in the early 1980s, but beginning with a report from a Texas study (Read \& Camp 1986), numerous scientists as well as producers, especially in the southern portion of the primary USA tall fescue region, soon found that the persistence of tall fescue was much poorer once the endophyte had been removed from the grass. A review of reports from scientists working with tall fescue provided evidence that endophyte-free tall fescue is agronomically inferior in numerous respects to endophyte-infected fescue (Pedersen et al.1990).

By the late 1990s, the tall fescue/endophyte/animal relationship had largely been defined and many related research challenges had been identified, but livestock producers faced a dilemma. It was widely recognised that most tall fescue in the USA had a high level of toxic endophyte infection that was causing widespread lowering of the performance of grazing animals, but equally clear that the endophyte was benefiting tall fescue plants by enhancing pest resistance and stress tolerance (Bouton 2000). Progress had been made, and knowledge of the effects of fescue endophyte toxins on grazing animals had caused many livestock producers to change their management of tall fescue and/or their grazing animals (Ball 1997), but there was no complete or permanent solution to the problem.

\section{Methods}

Bacon \& Siegel (1988) first proposed that fungal endophytes might be modified to produce only beneficial properties such as improved stress tolerance when inserted into an endophytefree tall fescue plant to produce a superior forage grass without causing toxicity problems. AgResearch in New Zealand, in collaboration with the University of Georgia, USA pursued the novel approach of identifying and selecting naturally occurring, non-toxic endophyte strains for later re-infection into elite tall fescue cultivars (Latch 1997). AgResearch's endophyte research group screened hundreds of strains of endophyte to identify those that expressed no production of toxic ergovaline and moderate to high levels of beneficial peramine and loline alkaloids.

The University of Georgia developed and released two tall fescue cultivars, Georgia 5 and Jesup, for use in the southeastern USA (Bouton et al.1993b; Bouton et al.1997). Their excellent agronomic performance when infected with endophytes (Bouton et al. 1993a) made them good candidates for the strategy of killing the toxic resident endophyte in their seeds and re-infecting their seedlings with non-toxic (i.e. non-ergot producing) endophytes. Patented non-toxic $N$. coenophialum strains (Latch et al. 2000) were inserted into a random sample of several hundred 
seedlings of endophyte-free Jesup and Georgia 5 tall fescue using procedures of Latch \& Christensen (1985).

Several strains were assessed for host compatibility, ergot alkaloid production, endophyte transmission into seed, and agronomic performance (Bouton et al. 2000; Bouton et al. 2002). As there are many strains of naturally occurring non-toxic endophytes, and they vary in their ability to work effectively with different tall fescue cultivars, lengthy testing is necessary to determine the stress tolerance of a particular endophyte/tall fescue cultivar combination.

One strain, later named MaxQ ${ }^{\mathrm{TM}}$, emerged from these tests as particularly successful and was made commercially available in both the Jesup and Georgia 5 cultivars. After more extensive testing, the Georgia 5/MaxQ $\mathrm{Q}^{\mathrm{TM}}$ endophyte/tall fescue combination was determined to be a less viable match and was removed from the commercial market. Jesup $\mathrm{MaxQ}^{\mathrm{TM}}$ is a synthetic combination of a superior tall fescue forage grass cultivar (Jesup) and a nontoxic endophyte and is marketed in the USA by Pennington Seed Inc. of Madison, Georgia.

Research conducted before commercial availability of the first novel endophyte tall fescue had established that the novel endophyte concept was sound (Bouton et al. 2000; Bouton et al. 2002). Because of the importance of tall fescue as a forage species there was immediate interest in novel endophyte tall fescue by scientists, extension workers and other farm advisors, and by forage/livestock producers. As a result, to date at least 25 grazing research experiments and over 150 on-farm demonstrations have been conducted with novel endophyte tall fescue in the USA.

\section{Results}

Given the stand persistence problems that had occurred with most plantings of endophyte-free tall fescue, there was widespread concern about persistence of novel endophyte tall fescue. Interestingly, the year 2000 (the first year seed MaxQ ${ }^{\mathrm{TM}}$ was widely available for testing) was one of the driest on record in much of the primary tall fescue growing region of the USA, which did not bode well for new plantings. Despite this severe early test, in most cases fields planted in autumn 1999 developed strong stands, as has been the case with most plantings in subsequent years.

In research trials, novel endophyte tall fescue has resulted in animal performance similar to that previously been obtained with endophyte-free stands (Bouton et al. 2002; Nihsen et. al. 2004; Parish et al. 2003a; Parish et al. 2003b; Watson et al. 2004). Livestock producers who have planted novel endophyte tall fescue have also obtained outstanding animal performance without occurrence of the disorders traditionally associated with the grass. In addition, persistence of novel endophyte tall fescue stands has been similar to the level of persistence producers had come to expect from Kentucky 31 .

\section{Discussion}

Introduction of a new agricultural technology is often problematic. Many thousands of livestock producers in the USA use, or have the potential to use, tall fescue to provide nutrition for grazing animals, so getting information on any new technology (especially such a multi-faceted one) to a high percentage of them is a challenge. Even when an educational message has been successfully delivered and understood, there often is a good deal of resistance to acceptance of the new technology by producers. In the case of novel endophyte tall fescue, the poor stand persistence many producers had with endophyte-free tall fescue loomed as a formidable psychological barrier to acceptance.
Another unique challenge associated with the commercial introduction of novel endophyte tall fescue was that the tall fescue endophyte is actually a fragile organism that is less tolerant of heat and humidity extremes than the seed in which it is transmitted. Thus, to ensure a high percentage of novel endophyte infection, the identity of the special endophyte strain would need to be monitored, and its viability would need to be protected, during the processes of seed production, packaging, handling, and marketing.

In the 7 years since novel endophyte tall fescue first became commercially available, there has been a significant level of acceptance of this technology. An estimated 121,000 hectares of $\mathrm{MaxQ}^{\mathrm{TM}}$, plus a small area of one other commercially-available novel endophyte, have been established in at least 35 American states. There appear to have been a number of important reasons why novel endophyte technology has been well accepted.

Animal performance trials and grazing persistence studies, initiated before commercial availability of the first novel endophyte, had established that the concept was sound. Because of the importance of tall fescue as a forage species there was much interest shown by scientists, extension workers and other farm advisors, as well as forage/livestock producers in this new product. The results from these plantings have overwhelmingly been positive, thus giving producers confidence in novel endophyte technology.

Special attention is required to protect a novel endophyte in tall fescue seed. In the case of $\mathrm{MaxQ}^{\mathrm{TM}}$ tall fescue, for example, this has included pre- and post-harvest quality assurance testing for endophyte viability, the development and use of a special laminated foil bag that better protects both seed and endophyte from heat and humidity, special care to keep the bags in a favourable environment from seed harvest through retail marketing, and marketing of all seed labelled as being novel endophyte material within 10 months of seed harvest.

Special approaches to quality control such as those just mentioned necessarily lead to increases in seed cost to producers. Consequently, novel endophyte seed has typically cost producers three to four times more than other tall fescue seed, but the substantially higher cost of novel endophyte seed may have caused them to use greater care in planting it and in managing seedling stands.

Given the magnitude of the reduction in animal gains, milk production, and reproduction caused by toxic tall fescue, livestock producers have a strong incentive to reduce or eliminate these problems. The scope of the problem is immense. It is estimated that over 8.5 million beef cows and at least 700,000 horses, plus many other types of domestic animals and wildlife graze tall fescue pastures (Ball et al. 2002). Numerous strategies or approaches have been shown to be of benefit in reducing toxic endophyte effects at least in some situations as summarised in a recent review (Roberts \& Andrae 2004), but the only real longterm solution is to plant novel endophyte tall fescue. Based on the good level of acceptance of this technology and the steady increase in its use during the past 7 years, it appears likely that various novel endophyte strain / tall fescue cultivar combinations will be used to an even greater extent on farms in the USA in the future.

\section{REFERENCES}

Bacon, C.W.; Lyons, P.C.; Porter, J.K.; Robbins, J.D. 1986. Ergot toxicity from endophyte-infected grasses: a review. Agronomy Journal 78: 106-116. 
Bacon, C.W.; Porter, J.K.; Robbins, J.D.; Luttrell, E.S. 1977. Epichloe typhina from tall fescue grasses. Applied Environmental Microbiology 35: 576-581.

Bacon, C.W.; Siegel, M.R. 1988. Endophyte parasitism of tall fescue. Journal of Production Agriculture 1:45-55.

Ball, D.M. 1997. Significance of endophyte toxicosis and current practices in dealing with the problem in the United States. pp. 395-410. In: Neotyphodium/Grass Interactions, Eds. Bacon, C.W.; Hill, N.S., Plenum Press, New York, NY.

Ball, D.M.; Hoveland, C.S.; Lacefield, G.D. 2002. Fescue toxicity. pp.198-205 In: Southern Forages (third edition). Potash \& Phosphate Institute, Norcross, GA.

Bouton, J. 2000. The use of endophytic fungi for pasture improvement in the USA. pp. 163-168. In: Proceedings of the $4^{\text {th }}$ International Neotyphodium/Grass Interactions Symposium. Eds. Paul, V.H.; Dapprich, P.D. Soest, Germany, 27-29 September.

Bouton, J; Hill, N; Hoveland, C.; McCann, M.; Thompson, F.; Hawkins, L.; Latch, G. 2000. Performance of tall fescue cultivars infected with non-toxic endophytes. pp. 179-185. In: Proceedings of the $4^{\text {th }}$ International Neotyphodium/Grass Interactions Symposium. Eds. Paul, V.H.: Dapprich, P.D. Soest, Germany, 27-29 September.

Bouton, J.; Hill, N.; Hoveland, C.; McCann, M..; Thompson, F.; Hawkins, L.; Latch, G. 2000. Performance of tall fescue cultivars infected with non-toxic endophytes. pp. 179-185. In: Proceedings of the $4^{\text {th }}$ International Neotyphodium/Grass Interactions Symposium. Eds. Paul, V.H.; Dapprich, P.D. Soest, Germany.

Bouton, J.H.; Latch, G.C.M.; Hill, N.S.; Hoveland, C.S.; McCann, M.A.; Watson, R.H; Parish, J.A.; Hawkins, L.L.; Thompson, F.N. 2002. Reinfection of tall fescue cultivars with non-ergot alkaloid-producing endophytes. Agronomy Journal 94: 567-574.

Bouton, J.H.; Duncan, R.R.; Gates, R.N.; Hoveland, C.S.; Wood, D.T. 1997. Registration of 'Jesup' tall fescue. Crop Science 37: 1011-1012.

Bouton, J.H.; Gates, R.N.; Belesky, D.P.; Owsley, M. 1993a. Yield and persistence of tall fescue in the southeastern coastal plain after removal of its endophyte. Agronomy Journal 85: 52-55.

Bouton, J.H.; Gates, R.N.; Hill, G.M.; Owsley, M.; Wood, D.T. 1993 b. Registration of Georgia 5' tall fescue. Crop Science 33: 1045.

Buckner, R.C.; Powell, J.B.; Frakes, R.V. 1979. Historical Development. pp. 1-8. In: Tall Fescue. Eds. Buckner, R.C.; Bush, L.P.; American Society of Agronomy Monograph No. 20, Madison, WI.

Fergus, E.N.; Buckner, R.C. 1972. Kentucky 31 fescue- culture and use. 1972. Registration of Kentucky 31 tall fescue. (Reg. No. 7). Crop Science 12: 714.

Hoveland, C.S.; Schmidt, S.P.; King, C.C. Jr.; Odom, J.W.;
Clark, E.M.; McGuire, J.A.; Smith, L.A.; Grimes, H.W.; Holliman, J.L. 1983. Steer performance and association of Acremonium coenophialum fungal endophyte on tall fescue pasture. Agronomy Journal 75: 821.824.

Latch, G.C.M. 1997. An overview of Neotyphodium/Grass interactions. p. 1-11. In: Neotyphodium/Grass Interactions. Eds. Bacon, C.W.; Hill, N.S. Plenum Press, New York.

Latch, G.C.M.; Christensen, M.J. 1985. Artificial infection of grasses with endophytes. Annals of Applied Biology 107:17-24.

Latch, G.C.M.; Christensen, M.J.; Tapper, B.A.; Easton, H.S.; Hume, D.E.; Fletcher, L.R. 2000. Tall fescue endophytes. U.S. Patent 6111 170. Date issued: 29 August.

Nihsen, M.E.; Piper, E.L.; West, C.P.; Crawford, R.J.; Denard, T.M.; Johnson, Z.B.; Roberts, C.A.; Spiers, D.A.; Rosenkrans, C.J. Jr. 2004. Growth rate and physiology of steers grazing tall fescue inoculated with novel endophytes. Journal of Animal Science 82: 878-883.

Parish, J.A.; McCann, M.A.; Watson, R.H.; Hoveland, C.S.; Hawkins, L.L.; Hill, N.S.; Bouton, J.H. 2003a. Use of nonergot alkaloid-producing endophytes for alleviating tall fescue toxicosis in sheep. Journal of Animal Science 81: 1316-1322.

Parish, J.A.; McCann, M.A.; Watson, R.H.; Paiva, N.N.; Hoveland, C.S.; Parks, A.H.; Upchurch, B.L.; Hill, N.S.; Bouton, J.H. 2003b. Use of non-ergot alkaloid producing endophytes for alleviating tall fescue toxicosis in stocker cattle. Journal of Animal Science 81: 2856-2868.

Pedersen, J.F.; Lacefield, G.D.; Ball, D.M. 1990. A review of the agronomic characteristics of endophyte-free and endophyteinfected tall fescue. Applied Agricultural Research 5: 188-194.

Read, J.C.; Camp, B.J. 1986. The effect of the fungal endophyte Acremonium coenophialum in tall fescue on animal performance, toxicity, and stand maintenance. Agronomy Journal 8: 811-814.

Roberts,C.; Andrae, J. 2004. Tall fescue toxicosis and management. Online. Crop Management 10: 1094/CM-20040427-01-MG.

Schmidt, S.P.; Osborn, T.G. 1993. Effects of endophyte-infected tall fescue on animal performance. Agriculture Ecosystems and Environment 44: 233-262.

Shelby, R.A.; Dalrymple, L.W. 1987. Incidence and distribution of the tall fescue endophyte in the United States. Plant Disease 71: 356-361.

Stuedemann, J.A.; Hoveland, C.S. 1988. Fescue endophyte: history and impact on animal agriculture. Journal of Production Agriculture 1: 39-60.

Watson, R.H.; McCann, M.A.; Parish, J.A.; Hoveland, C.S.; Thompson, F.N.; Bouton, J.H. 2004. Productivity of cow-calf pairs grazing tall fescue pastures infected with either the wildtype endophyte or a nonergot alkaloid-producing endophyte strain, AR 542. Journal of Animal Science 82: 3388-3393. 